\title{
Seismic Response of Sri Lanka using PSHA Technique
}

\author{
S.B. Uduweriya, K.K. Wijesundara, P.B.R. Dissanayake, K.A.S. Susantha and \\ H.N. Seneviratne
}

\begin{abstract}
This paper describes a research study carried out to find the seismic response of Sri Lanka using Probabilistic Seismic Hazard Assessment (PSHA) considering seismic activities surrounding the region. Three attenuation relationships, namely Abrahamson and Silva, Raghukanth and Iyengar, and Campbell and Bozorgnia, verified to be reliable according to existing South Indian seismic data have been used in the analysis. The completeness check for the earthquake catalogue for Sri Lanka seismic scenario has been performed and 200 years of data were demonstrated to be satisfactory. PSHA technique was used with logic tree approach to minimize the effects of epidemic uncertainty. Then, Peak Ground Accelerations and Spectral Accelerations at bedrock level ignoring the overburden effects were computed for important cites in Sri Lanka and they were found to be highest in the west coastal zone within a range of 0.05 to $0.1 \mathrm{~g}$ and an approximate PGA value of $0.1 \mathrm{~g}$ in Colombo.
\end{abstract}

Keywords: Attenuation Relationships, Peak Ground Acceleration, Spectral Acceleration

\section{Introduction}

Sri Lanka is located within a tectonic plate known as "Indo-Australia plate". According to the historical records, very few number of earthquakes were recorded within the country. The seismic scenario of Sri Lanka in reference to oceanic earthquakes in NW to SW region has been described in detail by Seneviratne et al. (2019) [22]. At present there is little evidence to identify seismic hazards originating from the oceanic region from SW to NE. With the Sri Lankan landmass being solidly connected to South Indian plate, the impact of earthquakes originating from South India may be of importance. However, there has been little seismic activities in the southern oceanic region though some scholars [8] have pointed out the possibility of an oceanic plate boundary forming to the deep south of Sri Lanka. Impact of seismic activities around Sri Lanka may be predicted using Probabilistic Seismic Hazard Assessment (PSHA) technique. This paper describes a study of seismic response of Sri Lanka considering all surrounding seismic scenarios. The overall results of PSHA are compared herewith those obtained from Deterministic Seismic Hazard Assessment (DSHA) [22].

\section{Probabilistic Seismic Hazard Assessment (PSHA) Technique}

DSHA and PSHA are the commonly used techniques for the determination of seismic hazards. The procedure of DSHA technique has already been described by Reiter (1990) [20].
The basic procedure of PSHA was initially developed by Cornell (1968) [7] and its computerized form was implemented by Mc Guire (1976 and 1978) [10]. Modern PSHA has gradually evolved by incorporating additional terms and computational tools in order to represent seismic hazards more accurately. The basic methodology involves calculating how often a suite of specified levels of ground motion will be exceeded at the site. The general procedure for a Cornell-McGuire PSHA comprises four fundamental steps.

The first step involves the identification and delineation of all potential sources of seismicity that may affect the site of interest.

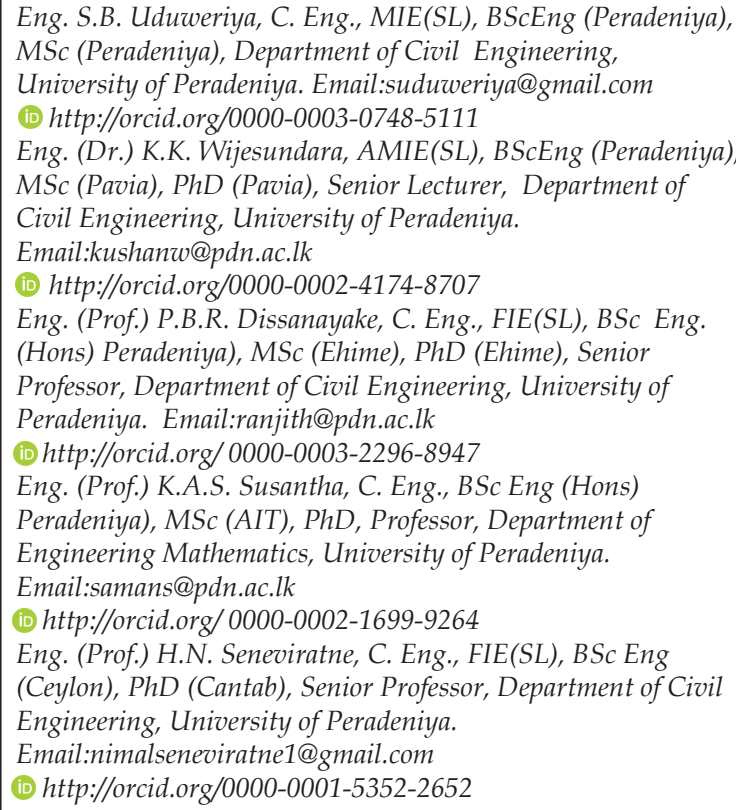


These sources of seismicity may be represented as area sources, fault sources, or point sources, depending upon the geological nature of the source and available data.

In the second step, the temporal behaviour of earthquakes is assumed to follow a Poissonian process and it is determined for each source by establishing a magnitude recurrence relationship over the range of magnitudes that are likely to be generated by each seismic source.

The third step involves the use of Ground Motion Prediction Equations (GMPEs) which are same as predictive relationships in DSHA, to establish the conditional probability of exceedance of a pre-specified ground motion value for each site given the occurrence of an earthquake of a particular magnitude and location. The final step of the analysis computes the annual number of events that produces a ground motion parameter, e.g. Spectral Accelerations (SA), that exceeds a specified threshold level, $\mathrm{z}$. This number of events per year is also called the "annual frequency of exceedance", and the inverse of it is called the "return period". Several probability distributions for each seismic source defined in the previous steps are determined from the past earthquake records.

\section{Earthquake Catalogue for the study}

An earthquake catalogue was compiled for an area bounded by latitudes $0^{\circ} \mathrm{N}$ to $20^{\circ} \mathrm{N}$ and longitudes $70^{\circ} \mathrm{E}$ to $90^{\circ} \mathrm{E}$ based on historical and instrumental earthquake data from 1063 AD to 2012. Data was collected from different sources such as Menon et al. (2010) [12], Chandra (1977) [6], Rao and Rao (1984) [19], Guha and Basu (1993) [13], Biswas and Majumdar (1997) [4], Iyengar et al. (1999) [5], Jaiswal and Sinha (2007) [16], Abayakoon (1996, 1998) [1], Peris (2007) [17], Rodriguez (1616) [21], Earthquake catalogue prepared by National Disaster Management Authority, New Delhi, India (2011) and internationally recognized earthquake databases on the internet, such as the National Earthquake Information Centre (NEIC), International Seismological Centre (ISC), Incorporated Research Institution for Seismology (IRIS), and the Geological Survey and Mines Bureau, Sri Lanka (GSMB). Duplicate events were manually detected and deleted.

This catalogue is shown in Figure 1 and a filtered version of this catalogue was used to describe the seismic scenario for oceanic earthquakes in the NW-SW in the region of Sri Lanka by Senevitatne et al. (2019) [22]. The completeness of the original catalogue has been verified by the authors following the procedure recommended by Stepp (1973) [23]. The above results shown in Figure 2 illustrate the completeness of the catalogue beyond 200 years.

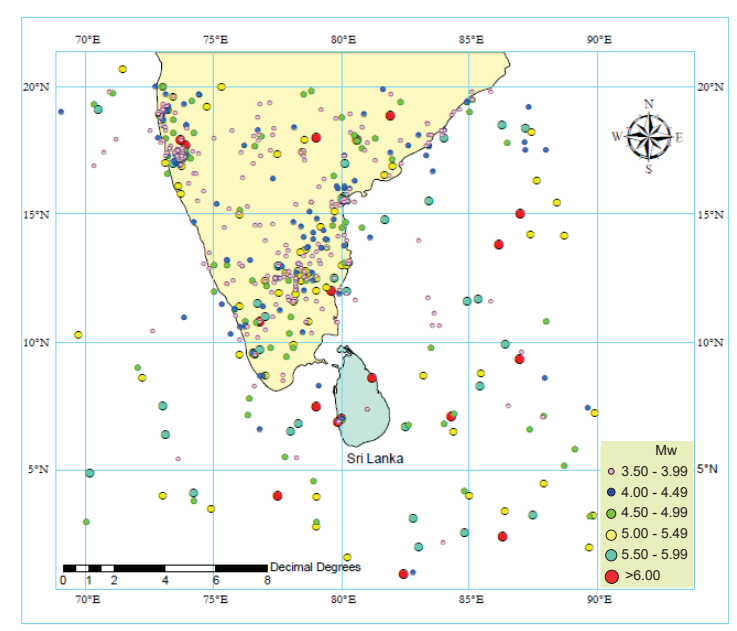

Figure 1 - Epicenters of past earthquakes

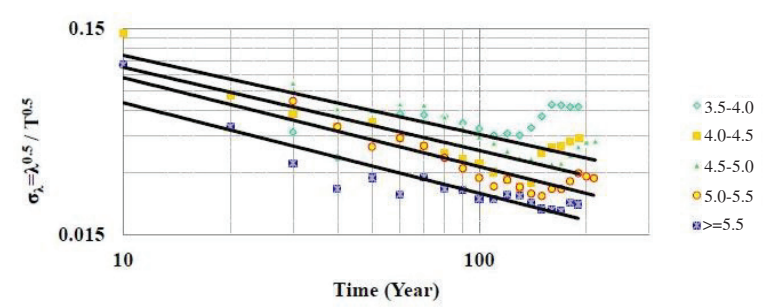

Figure 2 - Completeness time plots in terms of moment magnitude following Stepp (1973) [23] method. (Each symbol refers to a different magnitude range)

\section{Macrozonation studies}

Various researchers have studied the seismicity and tectonics within and outside of Sri Lanka in order to highlight the potential seismic hazard. Many Indian scientists have carried out studies to define seismic characteristics of peninsular India. Menon et al (2010) [12] had carried out a probabilistic seismic hazard macro-zonation of Tamil Nadu in Southern India in 2010. They have scientifically identified eleven seismogenic zones related to the Southern part of India around Tamil Nadu including Sri Lanka.

Based on above studies, a macro-zonation has been proposed by the authors to study seismic response of Sri Lanka as shown in Figure 3. The same seismogenic zones used by Menon et al. (2010) [12] has been used in this study except 
the Sri Lankan zone which is replaced by the line source of Comorin Ridge and Mannar lineament, the dominant seismic features of the zone. This is justified as very few earthquake records are available in the sea region from SW to NE; also according to Vitanage (1995) [24] and Fernando \& Kulasinghe (1986) [9] only micro seismic activities had originated within the country.

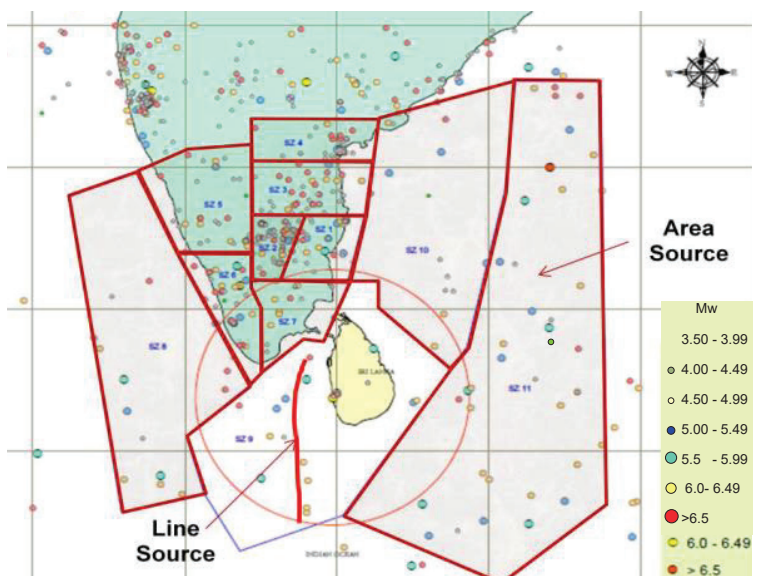

Figure 3 - Identified seismogenic zones

\section{Gutenberg \& Richter Relationships}

Following the steps of PSHA technique the probability of occurrence of earthquakes within each area source (macro zone) and the line source were determined from the earthquake catalogue [14]. As an example, Figure 4 defines the above relationship for the Comorin Ridge and Mannar lineament line source. The complete relationships (gradient and intercept) for all the sources determined from semi logarithmic plots of magnitude verses inverse of return period are given in Table 1.

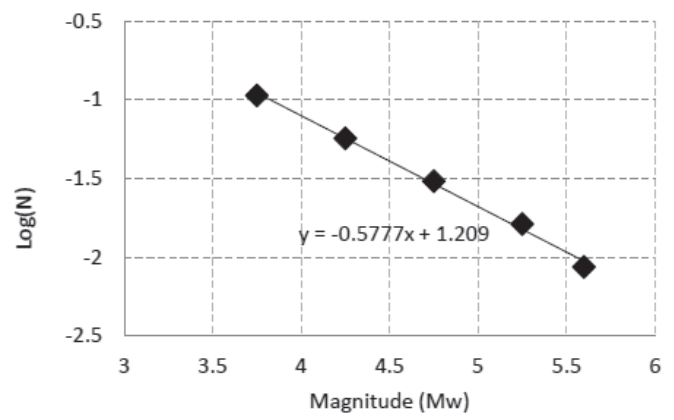

Figure 4 - Gutenberg - Richter Relationship for Comorin Ridge and Mannar lineament line source
Table 1 - The gradients $(a)$ and intercepts $(b)$ for all the sources

\begin{tabular}{|c|c|c|}
\hline Zone & $\mathbf{a}$ & $\mathbf{b}$ \\
\hline SZ 1 & 2.26 & 0.76 \\
\hline SZ2 & 2.82 & 0.83 \\
\hline ZS6 & 1.48 & 0.58 \\
\hline SZ7 & 1.09 & 0.52 \\
\hline SZ8 & 3.12 & 0.79 \\
\hline SZ9 & 1.21 & 0.58 \\
\hline SZ10 & 2.83 & 0.79 \\
\hline SZ11 & 3.68 & 0.86 \\
\hline
\end{tabular}

\section{Selection of Attenuation Relationships}

Attenuation relationships are used to determine the seismic response at a site within one area source due to an earthquake in another area source. It is assumed that an earthquake in another area source will occur at the point on the boundary between the two areas along the line which connects the area source. Therefore, the shortest distance to the area source boundary was used as epicentral distance in these attenuation relationships to calculate the Peak Ground Accelerations (PGAs) and Spectral Accelerations (SAs).

Three ground motion attenuation relationships were chosen in this study to derive the PGA and the SA values. The relationship by Abrahamson and Silva (1997) [3] was developed from earthquakes recorded worldwide, especially in the West and North America. The above relationship is recommended for use in the analysis of shallow crustal seismic events worldwide. Raghukanth and Iyengar (2007) [18] developed an empirical relationship for Peninsular India based on a stochastic seismological model and compared its predictions with instrumental data from Koyona (1967) and Bhuj (2001) earthquakes in India. In addition to the above two attenuation relationships, the attenuation relationship developed by Campbell and Bozorgnia (2008) [5] which is validated for western United States and similar tectonically active regions of shallow crustal faulting has been chosen for the current study. The selected attenuation relationships to predict the median response are:

(i). Abrahamson \& Silva (1997) [3]: Base form of the magnitude and distance dependence of the attenuation relationship is only considered in this study ignoring the effects of the fault type and sites located on the hanging wall. 
For $\boldsymbol{M} \leq \boldsymbol{c}_{1}$

$\ln \left(\frac{\boldsymbol{S}_{a}}{\boldsymbol{g}}\right)=\boldsymbol{a}_{1}+\boldsymbol{a}_{2}\left(\boldsymbol{M}-\boldsymbol{c}_{1}\right)+\boldsymbol{a}_{12}(8.5-\boldsymbol{M})^{n}+\left[\boldsymbol{a}_{3}+\boldsymbol{a}_{13}\left(\boldsymbol{M}-\boldsymbol{c}_{1}\right)\right] \ln \boldsymbol{R}$

For $M>c_{1}$

$\ln \left(\frac{\boldsymbol{S}_{a}}{\boldsymbol{g}}\right)=\boldsymbol{a}_{1}+\boldsymbol{a}_{4}\left(\boldsymbol{M}-\boldsymbol{c}_{1}\right)+\boldsymbol{a}_{12}(8.5-\boldsymbol{M})^{n}+\left[\boldsymbol{a}_{3}+\boldsymbol{a}_{13}\left(\boldsymbol{M}-\boldsymbol{c}_{1}\right)\right] \ln \boldsymbol{R}$

Where $a_{1}, a_{2}, a_{3}, a_{4}, a_{12}, a_{13}, c_{1}, c_{4}$ and $n$ are the coefficients given in Abrahamson \& Silva (1997) [3] for the period range of 0.01 second to 5 second. $M$ and $r_{\text {rup }}$ are the moment magnitude and the closest distance to the rupture plane, respectively.

$\boldsymbol{R}=\sqrt{\boldsymbol{r}_{\text {rup }}^{2}+\boldsymbol{c}_{4}^{2}}$

(ii). Raghukanth and Iyengar (2007) :

$\ln \left(\frac{S_{a}}{g}\right)=c_{1}+c_{2}(M-6)+c_{3}(M-6)^{2}-\ln r-c_{4} r+\ln \left(\varepsilon_{b r}\right)$

where $c_{1}, c_{2}, c_{3}$ and $c_{4}$ are coefficients of attenuation equation for Southern India given in Raghukanth and Iyengar (2007) [18]. $M$ and $r$ refer to moment magnitude and hypocentral distance, respectively. $\ln \left(\varepsilon_{b r}\right)$ is the error term. It is zero for the median response.

(iii).Campbell and Bozorgnia (2008) [5]: Only the magnitude and distance dependence terms of the attenuation relationship are considered in this study, ignoring the terms of the fault mechanism $f_{f t}$, hanging wall $f_{\text {hng }}$, site response $f_{\text {site }}$ and basin response $f_{\text {sed }}$ as:

$\ln \left(\frac{s_{a}}{g}\right)=f_{\text {mag }}+f_{\text {dis }}+f_{\text {ftt }}+f_{\text {hng }}+f_{\text {Site }}+f_{\text {sed }}$

$\boldsymbol{f}_{\text {mag }}=\left\{\begin{array}{cc}\boldsymbol{c}_{0}+\boldsymbol{c}_{1} \boldsymbol{M} ; & \boldsymbol{M} \leq 5.5 \\ \boldsymbol{c}_{0}+\boldsymbol{c}_{1} \boldsymbol{M}+\boldsymbol{c}_{2}(\boldsymbol{M}-5.5) ; & 5.5<\boldsymbol{M} \leq 6.5 \\ \boldsymbol{c}_{0}+\boldsymbol{c}_{1} \boldsymbol{M}+\boldsymbol{c}_{2}(\boldsymbol{M}-5.5)+\boldsymbol{c}_{3}(\boldsymbol{M}-6.5) ; & \boldsymbol{M}>6.5\end{array}\right\}$

$\boldsymbol{f}_{\text {dis }}=\left(\boldsymbol{c}_{4}+\boldsymbol{c}_{5} \boldsymbol{M}\right) \ln \left(\sqrt{\boldsymbol{R}_{R U P}^{2}+\boldsymbol{c}_{6}^{2}}\right)$

Where $c_{0}, c_{1}, c_{2}, c_{3}, c_{4}, c_{5}$ and $c_{6}$ are the coefficients given in Campbell and Bozorgnia (2008) for the period range of 0.01 second to 7.5 second. $M$ and $R_{R U P}$ are the moment magnitude and the closest distance to the rupture plane, respectively.

In the above equations, $S_{a}$ is the Spectral Acceleration and $g$, the gravitational acceleration.

Attenuation of ground motion predicted by these three relationships is compared with strong motion records of two earthquakes from
Peninsular India. Four strong motion records from the Jabalpur earthquake (1997) and Bhuj aftershock (2001), both of Magnitude Mw 5.7, have been used in the comparison of predicted and observed attenuation characteristics (Figure 5). As seen from the figure, predicted and observed behavior is similar and therefore, these attenuation relationships are used for subsequent analyses with equal weightage.

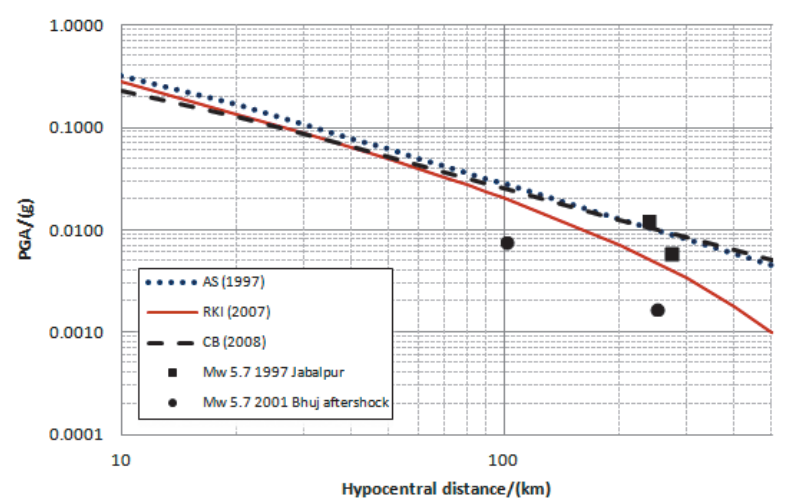

Figure 5 - The Comparison of predictions of ground motion attenuation relationships with instrumental data

Figure 6 illustrates the spectral accelerations predicted by the three selected attenuation relationships at 1 second. As seen from the figure, the predicted ground accelerations from the three attenuation relationships lie very close to each other at all epicentral distances of interest $(10-500 \mathrm{~km})$. Similar agreement was also obtained at 0.5 seconds.

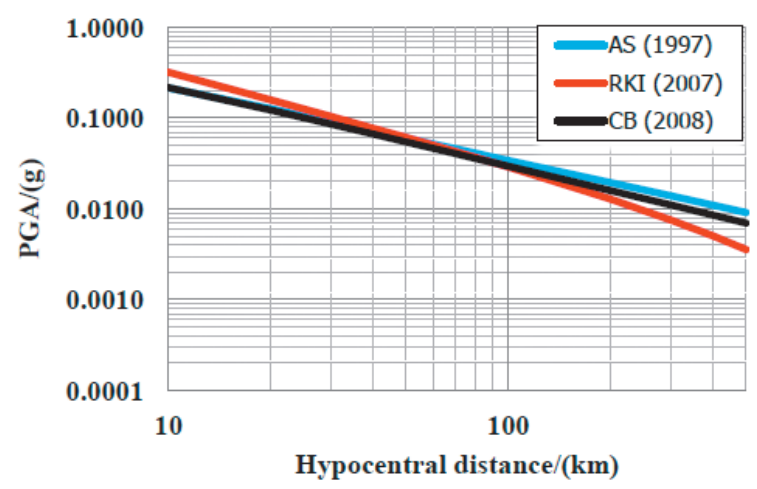

Figure 6 - The Comparison of predictions of ground motion attenuation relationships at $\mathbf{1}$ second period

\section{Logic Trees}

Logic tree methodology was used to address the epistemic uncertainty of various parameters and relationships in the PSHA calculation. The maximum cut off magnitude is based on the maximum historical earthquake (MHE) in each source zone of the earthquake catalogue. As an alternative, the MHE increased by 0.3 units has 
been considered. $60 \%$ of weight has been assigned to the maximum magnitude and balance $40 \%$ of weight was assigned to MHE increased by 0.3 units. For the selected attenuation relationships already described in previous section, it was difficult to assign a higher weight to one equation over the other due to closeness of prediction. Hence equal weightages have been assigned to all three relationships. Figure 7 shows this logic tree probability distribution.

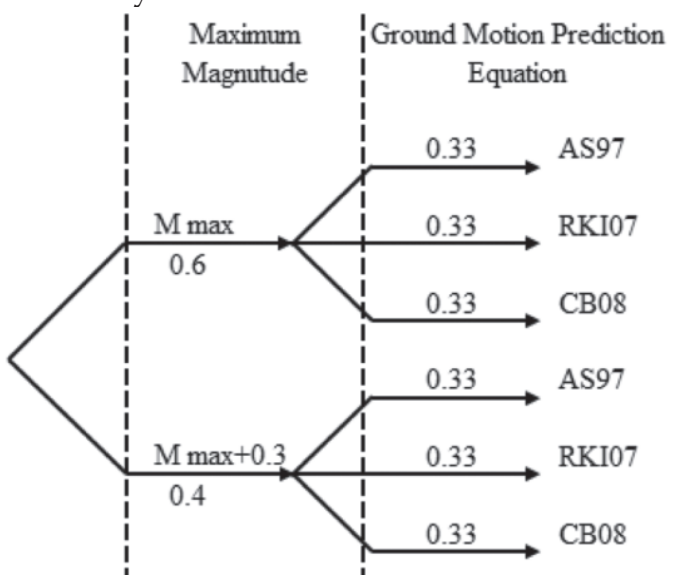

Figure 7 - Parameters and weightages adopted in the logic tree

\section{Calculation Procedure}

For each of the point of interest in the site, say point A (e.g. Colombo), the effect of the seismic activity in the surrounding source zones was modeled by placing the epicenters within the source zone but at the point closest to the point A. The magnitude of the earthquake was taken according to the return period considered (for e.g. 475 years) and the resulting spectral acceleration at $\mathrm{A}$ was calculated using the attenuation relationships and the logic trees described in Sections 6 and 7. The resultant bedrock response spectrum at point $\mathrm{A}$ was taken as the envelope of all the response spectra obtained in the above manner. PGA at point A is the intercept of response spectrum at zero period.

\section{Results and Discussion}

Table 2 shows the magnitude of PGA at bed rock level for 50, 475 and 2475 year return periods at twenty major cities in Sri Lanka. The results show that the PGA in Colombo for 50, 475 and 2475 year return periods is $0.025 \mathrm{~g}$, $0.107 \mathrm{~g}, 0.207 \mathrm{~g}$, respectively. Figures 8, 9 and 10 illustrate the hazard maps for PGA based on the probabilistic seismic hazard assessment for 50, 475 and 2475 year return periods. Furthermore, Figure 11 illustrates the calculated
$5 \%$ elastic damping Response Spectra (RS) for 50 year, 475 year and 2475 year return periods at bed rock level in Colombo. Similarly, the response spectra at other major cities in Sri Lanka were calculated.

Table 2 - PGA at different cities in Sri Lanka for 50,475 and 2475 year return periods

\begin{tabular}{|l|l|l|l|}
\hline \multirow{2}{*}{ City } & \multicolumn{3}{|c|}{ PGA (g) } \\
\cline { 2 - 4 } Ampara & $\mathbf{T = 5 0}$ & $\mathbf{T}=\mathbf{4 7 5}$ & $\mathbf{T = 2 4 7 5}$ \\
\hline Anuradhapura & 0.002 & 0.011 & 0.027 \\
\hline Badulla & 0.007 & 0.034 & 0.074 \\
\hline Batticaloa & 0.002 & 0.017 & 0.04 \\
\hline Colombo & 0.025 & 0.107 & 0.028 \\
\hline Dambulla & 0.004 & 0.025 & 0.056 \\
\hline Galle & 0.009 & 0.045 & 0.094 \\
\hline Hambantota & 0.003 & 0.016 & 0.038 \\
\hline Horana & 0.013 & 0.062 & 0.127 \\
\hline Jaffna & 0.041 & 0.158 & 0.325 \\
\hline Kandy & 0.005 & 0.025 & 0.057 \\
\hline Kurunegala & 0.007 & 0.035 & 0.076 \\
\hline Mannar & 0.033 & 0.134 & 0.28 \\
\hline Matara & 0.005 & 0.028 & 0.061 \\
\hline Mullaitivu & 0.008 & 0.04 & 0.101 \\
\hline Nuwara Eliya & 0.004 & 0.022 & 0.05 \\
\hline Polonnaruwa & 0.003 & 0.018 & 0.042 \\
\hline Puttalam & 0.029 & 0.122 & 0.233 \\
\hline Rathnapura & 0.006 & 0.033 & 0.073 \\
\hline Trincomalee & 0.009 & 0.026 & 0.048 \\
\hline
\end{tabular}

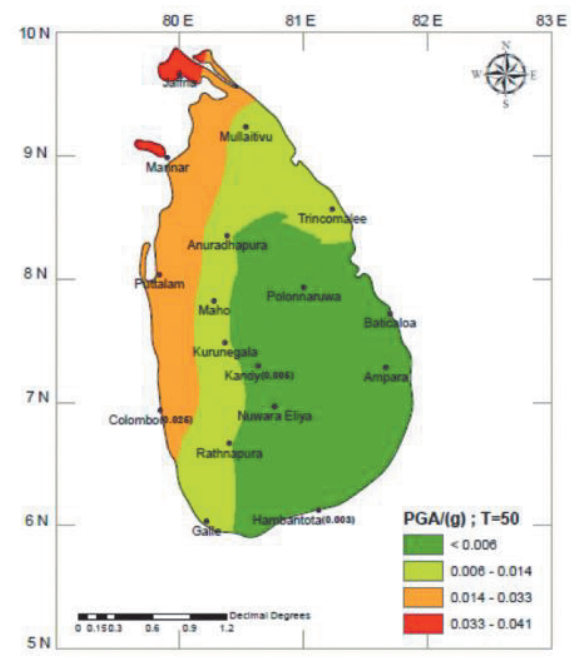

Figure 8 - SL Hazard map for PGA at 50 year return period 


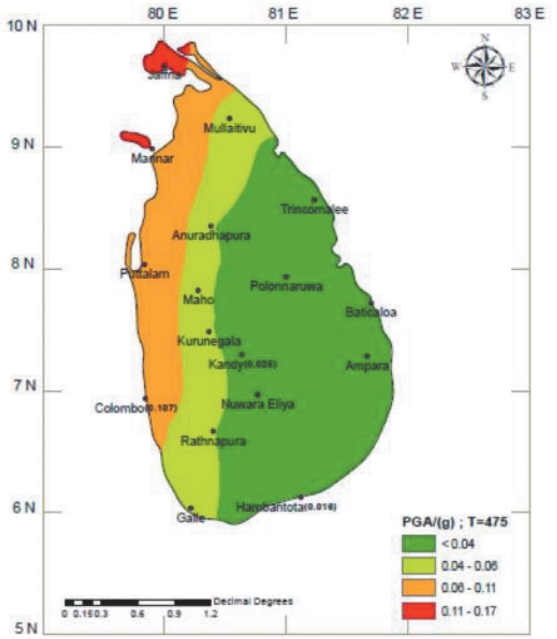

Figure 9 - SL Hazard map for PGA at 475 year return period

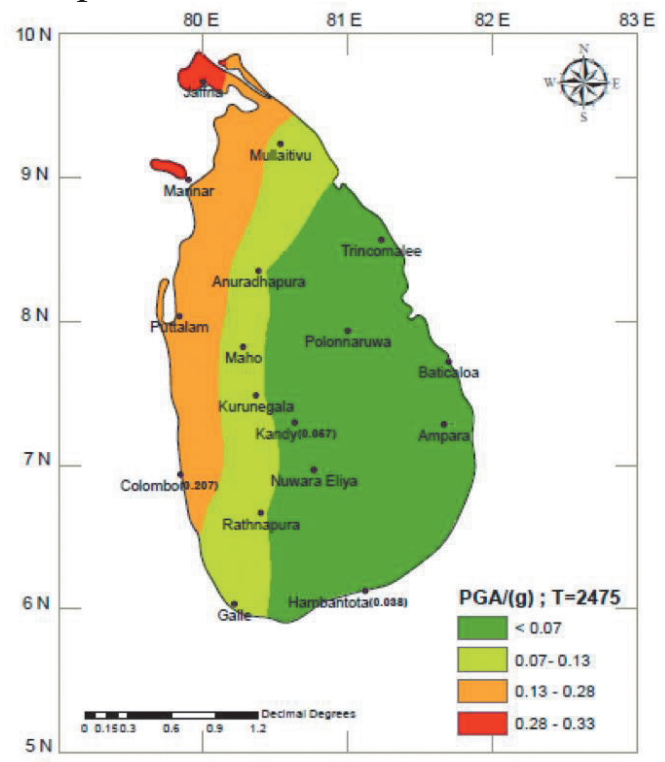

Figure 10 - SL Hazard map for PGA at 2475 year return period

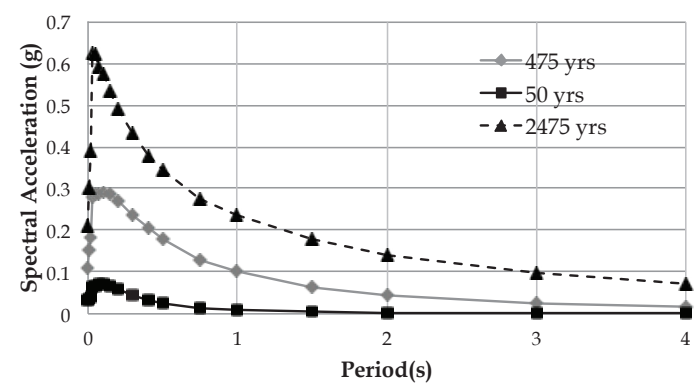

Figure 11 - Response spectra for 50, 475 and 2475 year return periods for Colombo city

PGA across Sri Lanka is in the range of 0.05-0.1 $\mathrm{g}$ for the 475-year return period event and in the range of $0.07-0.3 \mathrm{~g}$ for 2475 -year return period event. The PGA hazard maps clearly illustrate that PGA at bedrock level in Sri Lanka decreases in the West-East direction while it is fairly constant in the North-South direction. This is evident due to the fact that the effect of the line source of Comorin Ridge and Mannar lineament, the dominant seismic features of the zone become dominant in the PGA map (as well as spectral acceleration maps) for the 475 and 2,475-year return period events.

In comparison of PGA for 475 year return period event, at selected major cities in Sri Lanka with the earlier studies carried out by Abayakoon (1996) [1] and Peiris (2007) [17], a significant difference in the estimated hazard distribution is observed. This may be due to the use of the GMPEs as appropriate for different seismotectonic regimes. Furthermore, study has used multiple models for the seismogenic sources including a line source representing epicentres of past earthquakes in Comorin Ridge and Mannar lineament.

\section{Conclusions}

In this study, an improved seismic hazard assessment is performed for Sri Lanka incorporating new earthquake catalogue and zonation approach, ground motion prediction equations, and treatment of the inherent uncertainties. The new catalogue is compiled for area bounded by latitudes $0^{\circ} \mathrm{N}$ to $20^{\circ} \mathrm{N}$ and longitudes $70^{\circ} \mathrm{E}$ to $90^{\circ} \mathrm{E}$ based on historical and instrumental earthquake data from 1063 to 2012. For the new zonation approach, eleven seismogenic area source zones and one line source were defined. The GMPEs are validated with the past earthquake data for their predictions in the South Indian region. Epistemic uncertainty in the computed seismic hazard is accounted for within a logic tree framework with alternatives for time completeness analyses, maximum cut-off magnitude and GMPEs.

Peak Ground Acceleration (PGA) for rocky or hard soil sites in Sri Lanka varies from $0.1 \mathrm{~g}$ in West coastal line to $0.05 \mathrm{~g}$ in the East coastal line for the 475-year return period event while it is fairly constant in the North-South direction. This is mainly due to the fact that effect of line source of Comorin Ridge and Mannar lineament, the dominant seismic features of the zone, becomes dominant in the PGA map (as well as spectral acceleration maps) for the 475 return period event. Also, 5\% elastic damping response spectrum was proposed for rocky or hard soil sites based on the results obtained.

Furthermore, the present results indicate that the hazard distribution in Sri Lanka is significantly higher than that specified previously by Abayakoon (1996) and Peiris (2007). This may due to the use of GMPEs as 
appropriate for different seismotectonic regimes for which multiple models including a line source representing epicentres of past earthquakes in Comorin Ridge and Mannar lineament were considered.

\section{References}

1. Abayakoon S. B. S. (1996). "Seismic Risk Analysis of Sri Lanka", Journal of the Geological Society of Sri Lanka, Vol. 6, 65-72.

2. Abayakoon, S. B. S. (1998). "Seismic Response of Low Lying Areas in Colombo, Sri Lanka", Journal of the Institute of Engineers Sri Lanka, Vol. 28, no.2, 29-36.

3. Abrahamson, N. A. and W. J. Silva (1997). "Empirical Response Spectral Attenuation Relations for Shallow Crustal Earthquakes", Seismological Research Letter, Vol. 68, No. 1, 94127.

4. Biswas, S. and Majumdar, R. K. (1997). "Seismicity and Tectonics of the Bay of Bengal: Evidence for Intraplate Deformation of the Northern Indian Plate", Tectonophysics, Vol. 26, no. 9, pp. 323-336.

5. Campbell, K. W. and Bozorgnia Y. (2008). "NGA Ground Motion Model for the Geometric Mean Horizontal Component of PGA, PGV, PGD and 5\% Damped Linear Elastic Response Spectra for Periods Ranging from 0.01 to $10 \mathrm{~s}$ ", Earthquake Spectra, Vol. 24, no. 1, pp. 139-171.

6. Chandra, U. (1977). "Earthquakes of Peninsular India - A Seismotectonic Study", Bulletin of the Seismological Society of America, Vol. 87, no. 5, pp. 1387-1413

7. Cornell, C. A .(1968). “Engineering Seismic Risk Analysis", Bulletin of the Seismological Society of America, Vol. 58, no. 5, pp. 1583-1606.

8. Dissanayake, C. B. (2005). “A New Plate Boundary near Sri Lanka; Implications for Future Geo Hazards". Journal of the National Science Foundation of Sri Lanka, vol. 33, no. 1, pp. 5-8.

9. Fernando, M. J. and Kulasinghe, A. N. S. (1986). "Seismicity of Sir Lanka", Physics of the Earth and Planetary Interiors, Vol. 44, pp. 99-106.

10. McGuire, R. K. (1976) "FORTRAN Computer Program for Seismic Risk Analysis", U.S. Geological Survey Open-File Report, pp. 76-67.

11. McGuire R. K. (1978) "FRISK: Computer Program for Seismic Risk Analysis using Faults as Earthquake Sources", U.S. Geological Survey Open-File Report, pp. 78-1007.
12. Menon A., Ornthammarath T., Corigliano M. and Lai C. G. (2010). "Probabilistic Seismic Hazard Macrozonation of Tamil Nadu in Southern India", Bulletin of the Seismological Society of America, Vol. 1, no. 3, pp. 1320-1341.

13. Guha, S. K. and Basu, P. C., (1993). "Catalogue of Earthquakes $(M \geq 3$. ) in Peninsular India", Tech. Document No. TD/CSE-1, Atomic Energy Regulatory Board, Mumbai, India, pp. 1- 70.

14. Gutenberg, B. and Richter, C. F. (1954). "Seismicity of the Earth and Associated phenomena", $2^{\text {nd }}$ edition, Princeton University Press, Princeton.

15. Iyengar, R. N., Sharma, D. and Siddiqui, J. M. (1999). "Earthquake History of India in Medieval Times", Indian Journal of History of Science, Vol. 34, no. 3., pp. 181-237.

16. Jaiswal, K. and Sinha, R. (2007). “Probabilistic Seismic-Hazard Estimation for Peninsular India", Bulletin of the Seismological Society of America, Vol. 97, no. 1, pp. 318-330.

17. Peiris, L. M. N., (2007). "Seismic Hazard Assessment of Sri Lanka and Seismic Risk in Colombo", Risk Management Solutions, London, UK

18. Raghukanth, S. and Iyengar, R. (2007). "Estimation of Seismic Spectral Acceleration in Peninsula India", Journal of Earth System Sciences, Vol. 116, no. 3, pp. 199-214.

19. Rao, R. B. and Rao, S.P. (1984). "Historical Seismicity of Peninsular India," Bulletin of the Seismological Society of America, Vol. 74, no. 6, pp. 2519 - 2533.

20. Reiter, L. (1990). Earthquake Hazard Analysis: Issues and Insights, Columbia University Press, New York, NY.

21. Rodriguez, J. (1616). Relacion Verdadore del Esantoso Terremoto (True Description of the Terrible Earthquake). 4-page pamphlet, Lisboa.

22. Seneviratne, H. N., Perera, L. R. K., Wijesundara K. K., Dananjaya, R. M. S. and U de S Jayawardena (2019). Seismicity around Sri Lanka from Historical Records and its Engineering Implications, Journal of IESL, (under review).

23. Stepp, J. C. (1973). “Analysis of Completeness of the Earthquake Sample in the Puget Sound area, in Seismic Zoning", edited by S.T. Harding, NOAA Technical Report ERL 267-ESL30, Boulder, Colorado.

24. Vitanage, P. W. (1995). "Seismicity in Lineaments - Impact on Engineering Structures", In Handbook on Geology and Mineral Resources of Sri Lanka, Second South Asia Geological Congress, GEOSAS - II, pp. 59 - 62. 